\title{
O espelho quebrado
}

\author{
Mauricio Barreto Alvarez Parada*
}

Compagnon, Olivier. $O$ adeus à Europa: a América Latina e a Grande Guerra. Rio de Janeiro: Rocco, 2014.

Lançado no Brasil neste ano de rememoraçôes dos cem anos da Grande Guerra, o livro $O$ adeus à Europa: A América Latina e a Grande Guerra, do historiador francês Olivier Compagnon, contribui de forma muito instigante para os estudos sobre o conflito de 1914, pois o situa em um cenário pouco frequentado pelas pesquisas sobre o tema: a América Latina. Orginalmente um pesquisador do pensamento católico latino-americano, Compagnon estudou as relaçóes entre os intelectuais cristáos da Argentina e Brasil com os trabalhos de Maritain e Maurras. Assim sendo, seu olhar como historiador se formou com extrema sensibilidade para perceber a circulação de ideias, projetos e pessoas. Compangnon nos oferece, portanto, a possibilidade de adentrarmos no mundo das histórias conectadas e da história comparada.

É nesse registro que ele apresenta seu trabalho sobre a Grande Guerra. Como tese geral, ele nos oferece a inversão de perspectiva, "latinoamericanizando" o conflito. Ao traçar o impacto da guerra de 1914 na América Latina - na verdade suas fontes estão concentradas no Brasil e na Argentina o autor pretende estender a geografia imaginativa que ronda as teses sobre os eventos do conflito mundial do início do século XX. Compagnon afasta-se, claramente, dos argumentos que pensam o desastre de 1914 como uma "guerra civil europeia", sua proposta é levar avante a ideia de estudar um evento efetivamente mundial.

A presença da América Latina na historiografia da Primeira Grande Guerra é modesta, limitando-se a estudos de história militar, especialmente as poucas batalhas navais travadas na regiáo, ou aos estudos que se referem ao telegrama Zimmermann no que concerne a sua importância para a adesão dos Estados Unidos à guerra em abril de 1917. Segundo Compagnon: "Tudo se passa como se, afinal, a América Latina (...) tivesse naturalmente escapado do sismo da primeira guerra total da história simplesmente por estar-lhe à margem"' p. 15).

O historiador francês destaca que, apesar de o conflito ter sido um acontecimento matricial para a história contemporânea, é muito curioso que raros pesquisadores levaram a fundo a hipótese de que a Primeira Guerra Mundial poderia ser algo além de um nebuloso pano de fundo para a história latino-americana do século XX. Seu argu- 
mento é que a Grande Guerra não foi um evento marginal na história brasileira ou argentina e que o esquecimento que envolve a historiografia contrasta com a eloquência das fontes disponíveis.

A grande imprensa, os debates políticos, a produção intelectual, entre outros materiais documentais, demonstram o quanto a opinião pública da América Latina manteve-se atenta à evolução do conflito entre agosto de 1914 até a redefinição da configuração política decorrente dos tratados de paz e da criação da Liga das Nações. Além disso, a questão da neutralidade ou do apoio militar, os efeitos nas relações econômicas e, mesmo, a nova posição internacional dos Estados Unidos a partir de 1917 tornariam impossível que os anos 1914-1918 passassem despercebidos na história do "extremo Ocidente latino-americano"(p. 18).

Para sustentar sua argumentação, Compagnon divide seu livro em três partes, em cada uma delas ele procura desenvolver uma tese específica que se relaciona com a ideia geral do livro. A costura do trabalho está sustentada pelo recurso a uma expressiva diversidade de fontes. Textos de jornais, correspondência diplomática, mensagens presidenciais, textos literários são citados em todos os capítulos criando uma tessitura que torna a leitura fluida.

$\mathrm{O}$ autor inicia a obra com três capítulos reunidos em uma unidade intitulada "Da guerra europeia à guerra americana”. O grande tema dessa passagem é a recepção da guerra na América, momento em que o autor avalia os diversos posicionamentos frente à eclosão do conflito. $\mathrm{O}$ debate principal gira em torno das contendas entre germanófilos e aliadófilos acerca do posicionamento dos países americanos. Afinal, observa Compagnon, a neutralidade ou a adesão a um dos lados mobilizou diplomatas, juristas e repercutiu sobre a grande população de imigrantes europeus que constituiu um fluxo constante para a América Latina desde o século XIX.

Assim sendo, a mobilização dos diversos grupos que pertenciam às complexas sociedades latino-americanas constituiu "uma primeira etapa no duplo processo de mobilização das sociedades e de nacionalização do conflito" (p. 65). As fontes apresentadas por Compagnon apontam para uma tendência latino-americana favorável aos aliados da $E n-$ ténte, mas o próprio autor entende que essas vozes hegemônicas devem ser relativizadas.

Mais interessante do que isso, as fontes mostram uma forte solidariedade à França. As imagens mobilizadas nesses primeiros momentos da guerra colocariam de um lado a civilização francesa e de outro a bárbarie alemã, mostrando assim a tradicional face da aliança entre a América ibérica e a latinidade cristã francesa. Uma francofilia que apontaria para a ideia de que, portanto, o "destino da França na guerra seria uma metonímia do destino da humanidade" (p. 86).

O segundo grupo de capítulos, reunidos na segunda parte do livro e nomeados de "Europa Bárbara", é um ponto forte do livro. Compagnon argumenta que o imaginário latino-americano formou-se tendo como referência os conceitos europeus de civilização, cultura e modernidade — sejam eles de matriz inglesa, alemã ou francesa. $\mathrm{O}$ relato diário narrado nos jornais sobre os horrores 
da guerra realiza uma "forma de desilusão com relação à Europa que, metodicamente, parece ter orquestrado seu próprio fim" (p. 166). A imagem inicial, cheia de dissonâncias, mas hegemônica, de uma luta entre a civilizaçáo latina representada pela França contra o bárbaro alemão "é progressivamente substituída pela imagem de um desmoronamento da civilização europeia em seu conjunto" (p. 166).

Citando Leopoldo Lugones e Afrânio de Mello Franco, o autor observa que ambos se referem a esse período em termos semelhantes: o crepúsculo de uma civilização. Nesse quadro, a Grande Guerra se apresenta com a marca da desilusão, uma sociedade "desatinada ao sacrificar milhóes de indivíduos, imoral ao trair suas promessas [e] mentirosa ao falsificar a verdade que o cientificismo e o positivismo haviam (...) erigido em valor supremo da humanidade" (p. 208). Daí decorre, na análise de Compagnon, que os modelos europeus de modernidade se tornaram obsoletos e inválidos para a América Latina.

Os anos de 1914-1918 foram, então, o momento de uma grande inversáo de paradigma nas relaçôes entre a Europa e a América Latina. A guerra bárbara seria um sintoma do fracasso europeu e as "nações latino-americanas não poderiam continuar a tirar das fontes do outro lado do oceano as condiçóes e modalidades de sua própria modernidade" (p. 223). A Primeira Grande Guerra Mundial seria o momento de uma renovaçáo cultural da América Latina, uma segunda independência - "trata-se agora de levar a efeito uma emancipação intelectual [...] e de redescobrir as virtudes próprias a cada uma das naçôes do subcontinente" (p. 225).

Os três capítulos reunidos na terceira parte nomeada de "A Grande Guerra, a nação, a identidade" fecham o livro. Compagnon desdobra o argumento da crise do paradigma civilizacional europeu para a América Latina. Segundo ele, a crise cultural proporcionada pela Grande Guerra é um convite para repensar os elementos definidores da identidade das naçôes latino-americanas. Além disso, a desconstrução do eurocentrismo e a reavaliação das nacionalidades abrem caminho para novas concepçóes de modernidade no Brasil e na Argentina. Trata-se, no dizer do historiador francês, de uma "virada cultural' que merece ser avaliada com atenção. O deslocamento da "Europa como referência universal da modernidade e produtora de modelos destinados a suas periferias, convida a um sobressalto identitário" (p. 284). A Grande Guerra contribuiria decisivamente, no caso do Brasil, para gênese do modernismo de 1922, para formação do modelo teórico da democracia racial e para a modernização autoritária implementada pelo Estado Novo.

Assim exposto, o texto de "O adeus à Europa" nos coloca uma série de questionamentos. É inegável a qualidade da pesquisa empreendida por Compagnon, o uso das fontes mostra sua maturidade como historiador. No entanto, como um exercício de uma "história conectada" ele esbarra continuamente nas diferenças entre Brasil e Argentina. Mesmo ressaltando a forte circulação de ideias e intelectuais entre Rio de Janeiro e Buenos Aires - um exemplo sem- 
pre citado foi o discurso de Rui Barbosa em Buenos Aires em 1916 — o autor não consegue evitar a disparidade das posiçóes dos dois países frente ao conflito. $\mathrm{O}$ neutralismo do Governo Yrigoyen não encontra eco nas posiçóes brasileiras a favor dos franceses e seus aliados.

Bloqueado pelas diferenças regionais, o autor de $O$ adeus à Europa realiza um excelente trabalho de história comparada, mas a expectativa de uma história que explore redes e conexôes funcionais fica em parte frustrada.

A inserção da América Latina na historiografia da Grande Guerra e a "crise do paradigma europeu" são propostas que abrem possibilidades para muitas pesquisas futuras, no entanto, a terceira parte do livro parece forçar o argumento para além de suas possibilidades. Compagnon tem o cuidado de relativizar algumas de suas conclusôes, mas fazer da desilusão provocada pela Primeira
Grande Guerra Mundial o gatilho para entender as grandes mudanças das décadas de 1920 e 1930 ocorridas nos países da América Latina é dar início a uma argumentação que tem dificuldades para ser levada a frente.

A grande desilusão com a Europa deve ser considerada um fator para entender uma "guinada identitária", mas é difícil perceber na profundidade dessa ruptura os desdobramentos que sugere Compagnon. Afinal, temos que observar que os movimentos modernistas no Brasil e na Argentina dialogaram intensa e diversamente com as vanguardas europeias do entreguerras. Como entender o Estado Novo brasileiro sem a experiência política de Portugal e da Itália?

As questóes surgem, no entanto, como demonstração da qualidade da obra. O texto de $O$ adeus à Europa ocupa um importante lugar na historiografia recente sobre a Grande Guerra e também na historiografia latino-americana. 